\title{
História das abordagens científicas, médicas $e$ psicológicas sobre as transexualidades e suas aproximações críticas'
}

\section{History of scientific, medical and psychological approaches to transsexualities and their critical approach}

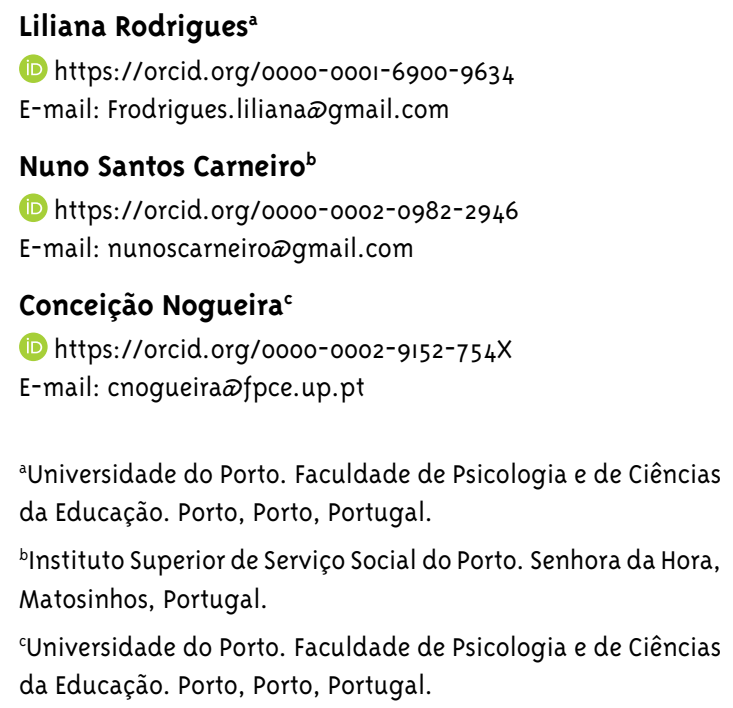

\section{Conceição Nogueirac}

(D) https://orcid.org/0000-0002-9152-754X

E-mail: cnogueiraळfpce.up.pt

aniversidade do Porto. Faculdade de Psicologia e de Ciências da Educação. Porto, Porto, Portugal.

'Instituto Superior de Serviço Social do Porto. Senhora da Hora, Matosinhos, Portugal.

'Universidade do Porto. Faculdade de Psicologia e de Ciências da Educação. Porto, Porto, Portugal.

\section{Resumo}

Neste artigo, apresenta-se um breve enquadramento histórico das abordagens científicas, médicas e psicológicas sobre as transexualidades, tecendo um conjunto de considerações sobre a forma como tal enquadramento foi fundacional da noção de patologia associada às pessoas trans e como tem sido responsável pela manutenção da patologização destes indivíduos no imaginário coletivo. Para atingir tal objetivo, é desenhado um mapa cronológico dos acontecimentos que têm vindo a marcar, ao longo da história, o estudo e a intervenção com as pessoas trans a partir do modelo biomédico, referenciando algumas das personalidades que, no contexto ocidental, tiveram responsabilidade nesta visão biomédica das pessoas trans. No final deste trabalho, apresentase a discussão em torno da (des)patologização das transexualidades a partir do surgimento do paradigma centrado nos direitos humanos das pessoas trans e em propostas de autodeterminação dos seus corpos e identidades.

Palavras-chave: Transexualidades; Modelo Biomédico; Psicologia Crítica; (Des)Patologização das Identidades Trans.

\section{Correspondência}


Abstract

This study provides a brief historical background of scientific, medical and psychological approaches to transsexualities. It also makes considerations on how such approaches based the concept of pathology that is associated with trans people and how it has been responsible for maintaining the pathologization in the collective imaginary. More specifically, we will establish a chronology of events that, throughout history, have affected the study on and the intervention with trans people, based on the biomedical model. We will also refer to some Western figures responsible for creating this biomedical vision of trans people. Finally, the discussion about the (de)pathologization of transsexualities is presented, based on the emergence of the paradigm centered on the human rights of trans people and proposals for self-determination of their bodies and identities. Keywords: Transsexualities; Biomedical Model; Critical Psychology; (De)Pathologization of Trans Identities.
Introdução: abordagens científicas, médicas e psicológicas sobre as transexualidades

A história das abordagens científicas, médicas e psicológicas sobre as transexualidades ${ }^{2}$ é antiga. No início do século XX, Magnus Hirschfeld (18681935), médico, sexólogo, judeu, alemão e homossexual, distinguiu a orientação sexual (na época, designada por "orientação do desejo") de identidade de gênero. ${ }^{3}$ Hirschfeld foi um dos pioneiros no uso do termo "transexual" e foi investigador no campo da homossexualidade e na variante do comportamento sexual (Mancini, 2010; Missé, 2014).

Para além de Magnus Hirschfeld, contam-se outros nomes na história das transexualidades, nomeadamente na história da endocrinologia, como Eugen Steinach e Hary Benjamin. Em 1910, Eugen Steinach descobre os efeitos morfológicos das hormonas sexuais e dedica-se a investigar em animais os transplantes de gônadas masculinas em fêmeas e vice-versa.

Após os estudos desenvolvidos por Steinach, Hirschfeld utiliza os resultados desses estudos para realizar a mudança de sexo em humanos. Em 1919, Magnus Hirschfeld cria o Institute for Sexual Science, em Berlim, onde realiza as primeiras cirurgias de mudança de sexo ao longo dos anos de 1920. Neste instituto, Felix Abraham foi o primeiro cirurgião a operar, em 1921, a primeira transexual, Dorchen Richter ${ }^{4}$ (Castel, 2001; Mancini, 2010). Em 1930, no mesmo local, a cirurgia de redesignação sexual (ainda que não abarcasse os mesmos procedimentos daquela que é efetuada atualmente) é realizada a Lili Elbe $^{5}$ (Hoyer, 1933/2004; Meyerowitz, 2002). Em 1933 ,

2 Nesta parte, usaremos predominantemente os termos "transexual" e "transexuais" para referir às pessoas com não conformidade entre o sexo e gênero, uma vez que estas designações têm sido adotadas pelo modelo médico ao longo do tempo. No caso de haver referência a outras designações, como "transvestismo" ou "transexualismo", estas visam explicar os seus contextos de surgimento. Destaca-se, porém, que algumas dessas designações podem não corresponder àquilo que atualmente significam. Também as designações “mudança de sexo" e/ou "cirurgia de redesignação sexual" têm sido usadas no contexto biomédico e a nível internacional, ainda que se reconheça a importância de adotar mudanças terminológicas que confiram uma maior pluralidade e diversidade a esses procedimentos, por exemplo, cirurgia de transgenitalização no contexto médico brasileiro.

30 termo "identidade de gênero" ainda não era usado no início do século XX.

4 A cirurgia de Dorchen Richter é conhecida pelo caso de Rudolf, no entanto, utilizaremos o nome de Dorchen porque nos referimos uma pessoa que se identificava no feminino, tendo escolhido o nome de Dorchen para se designar (Mancini, 2010).

5 Segundo Niels Hoyer, editor do livro Man into woman: the first sex change: a portrait of Lili Elbe, publicado em 1933, Lili Elbe foi uma pessoa intersexo (entenda-se por intersexo uma pessoa que tem características total ou parcialmente desenvolvidas de ambos os 
o instituto sofre com deliberação, por Adolf Hitler, da destruição do arquivo sediado.

Como foi referido anteriormente, as primeiras cirurgias conhecidas foram a de Dorchen Richter, em 1921, e a de Lili Elbe, em 1930. Contudo, o acontecimento que marca o nascimento da transexualidade, enquanto categoria nosológica, é a intervenção cirúrgica ${ }^{6}$ realizada na Dinamarca, em 1952, a Christine Jorgensen, ex-soldado do exército norte-americano.

Segundo Dave King (1998), Dorchen Richter foi a primeira pessoa a mudar de sexo no contexto ocidental, mas este caso não foi muito mediatizado. Antes de Christine Jorgensen ter realizado a cirurgia de redesignação sexual, em 1952, já tinham acontecido várias cirurgias na Alemanha, Suíça, Áustria, Suécia, Países Baixos, Dinamarca e Marrocos, contudo, foi apenas com a divulgação da prática da cirurgia de Christine Jorgensen em vários jornais estadunidenses (e.g. no New York Daily News, cujo titulo "Ex-GI becomes blonde beauty: operations transform Bronx youth" e no The Daily Mirror com o nome "Dear Mum and Dad, son wrote, I've now become your daughter") que, ao alargar a visibilidade desta prática, a tornou, exponencialmente, globalmente adotada pelo modelo médico de intervenção em pessoas que não conformavam as normas de gênero (Docter, 2008).

Apesar das cirurgias de redesignação sexual terem sido praticadas antes de 1960, é apenas nesta década que as questões ligadas à transexualidade ganham maior destaque na medicina, com Harry Benjamin (1954/2006). Em 1954, Benjamin populariza o termo "transexual" e o utiliza para distinguir as pessoas que desejam a cirurgia das que não a desejam (estas últimas consideradas pessoas travestidas ${ }^{7}$ ). Para além de introduzir o tema, define os primeiros critérios de diagnóstico da transexualidade no seu livro The transsexual phenomenon (Benjamin, 1966), o qual permitiu pensar esta categoria e trabalhá-la em contexto médico (Ortega, Romero-Bachiller; Ibáñez, 2014; Platero, 2014). A prática clínica de Benjamin, assim como as suas publicações, foram adotadas pela abordagem médica com pessoas transexuais (Benjamin, 1954/2006).

Enquanto Benjamin (1954/2006) defendia a intervenção cirúrgica como a resposta mais adequada para as situações de transexualidade, David Cauldwell não a apoiava (Soley-Beltran, 2009). Cauldwell (2006) designou por "psicopatia transexual" um estado psicológico no qual um indivíduo se sente e vive como um membro do sexo ao qual não pertence, o que significa, segundo tal posicionamento, que essa pessoa não é mentalmente saudável. ${ }^{8} \mathrm{O}$ trabalho de Cauldwell (2006) teve várias contradições pelo fato de rotular a transexualidade como psicopatia e admitir, simultaneamente, que existem pessoas transexuais perfeitamente adaptadas.

Entre as décadas de 1950 e 1970, começam a surgir as primeiras unidades médicas nas universidades norte-americanas destinadas às pessoas com não conformidade de gênero. Posteriormente, os programas universitários convertem-se em programas médicos e tratamentos hormonais e cirúrgicos começam a ser realizados. Os primeiros programas foram criados na Universidade da Califórnia de Los Angeles, em 1962, e na Universidade John Hopkins, em Baltimore, em 1966. Nesta altura, a cirurgia de redesignação sexual começa a disseminar-se por diferentes localizações dos EUA.

Em 1963, Reed Erickson inicia um processo de masculinização administrado por Harry Benjamin. Após a sua ligação com Harry Benjamin, Erickson contribuiu para a criação da The Erickson Educational Foundation e para as suas ligações com a World Professional Association for

sexos, Lili Elbe tinha órgãos internos não correspondentes ao sexo masculino), ainda que só tenha tido essa confirmação, de genitalidade ambígua atribuída, quando se assumiu como Lili Elbe. A menção que aqui se coloca é devida ao fato de Lili ter sido considerada uma das primeiras pessoas a fazer a cirurgia de redesignação sexual. Lili foi designada como homem no registo de nascimento e, posteriormente, identificou-se no feminino. Neste sentido, torna-se fundamental falar de Lili Elbe, mesmo sendo considerada uma pessoa intersexo, já que experienciou a inconformidade entre o sexo que lhe foi designado no registo de nascimento e o gênero ao qual sentia pertencer.

6 A prática das cirurgias da época de redesignação sexual não é a mesma da atualidade e mesmo esta prática médica varia consoante os/ as profissionais que a realizam. No caso de Christine Jorgensen, não se considerou a realização de uma reconstrução vaginal (designada atualmente por neovagina através da técnica de vaginoplastia).

7 Termo que designava as pessoas que vestiam roupas não conformes as normas de gênero na época.

8 Este conceito já tinha sido designado por Kraft-Ebbing no seu livro Psychopatia Sexualis. 
Trangender Health (WPATH), antiga Harry Benjamin International Gender Dysphoria Association (HBIGDA) criada em 1979 (Devor, 2013).

A HBIGDA publicou o primeiro protocolo oficial de tratamento de redesignação sexual, designado por Standards of Care Gender Identity Disorders (SOC), com o objetivo de fornecer aos/as profissionais de saúde linhas orientadoras para a decisão relativa ao encaminhamento dos/as transexuais para o processo de mudança física de sexo. Esta decisão passou, inicialmente, pela tentativa de distinguir os diferentes tipos de transexuais. Aos indivíduos que eram avaliados como "verdadeiros" transexuais, prescrevia-se o tratamento hormonal e cirúrgico, enquanto, para todos os outros, que não eram considerados "verdadeiros" transexuais, era recomendada psicoterapia para diminuir a disforia de gênero (APA, 2002; Nieder; Richter-Appelt, 2011). Vale dizer que Benjamin (1954/2006) já havia referido anteriormente que a psicoterapia não seria um tipo de intervenção adequada. ${ }^{9}$

Nas décadas de 1960 e 1970, surge na medicina um interesse crescente em explicar a homossexualidade, a transexualidade e a intersexualidade. Robert Stoller, Richard Green e John Money tiveram aqui um papel precursor no debate sobre os critérios que indivíduos tinham que cumprir para serem diagnosticados como transexuais e, por isso, aptos para as modificações corporais (Coll-Planas, 2010; Missé, 2014). Robert Stoller desenvolveu uma teoria sobre a origem da transexualidade e, na década de 1960, criou o Identity Center na Universidade da Califórnia de Los Angeles (Stoller, 1960/2006). Posteriormente, o mesmo professor desenvolveu trabalho na HBIGDA (Platero, 2014). Em 1973, Norman Fisk institui uma nosografia psiquiátrica para a transexualidade (Castel, 2001; Fisk, 1973).

Em 1980, a $3^{\text {a }}$ edição do DSM inclui, pela primeira vez, a transexualidade enquanto categoria "disforia de gênero" (APA, 1986). Em 1990, a transexualidade entra, pela primeira vez, no CID-2, da OMS, como "perturbação da identidade sexual", mais especificamente como “transexualismo” (Missé, 2014). Em 1994, o DSM-IV substitui a categoria "disforia de gênero" por "perturbação de identidade de gênero" (APA, 1994). Em 200o, na $4^{\text {a }}$ edição revista do DSM, a transexualidade mantém-se como "perturbação de identidade de gênero" (APA, 2002). Atualmente, a $5^{\text {a }}$ edição do Manual de Diagnóstico e Estatística das Perturbações Mentais (DSM-5) substitui a categoria de "perturbação de identidade de gênero" pela categoria “disforia de gênero" (APA, 2013).

A transexualidade mantém-se no CID-11 com a designação de "incongruência de gênero" (WHO, 2019). A OMS retira do CID a "perturbação da identidade sexual” (mais especificamente designado por "transexualismo"), do capítulo associado a doenças, passando a localizá-la como "incongruência de gênero" num outro capítulo associado a "outras condições relativas à saúde sexual” (WHO, 2019).

Estes modelos de classificações têm colocado as transexualidades como um problema do indivíduo e não têm problematizado a transfobia na sociedade. Por outras palavras, responsabiliza-se a pessoa pela não conformidade entre o sexo e o gênero, e não a sociedade pela transfobia (Arán; Zaidhaft; Murta, 2008). A leitura da transexualidade dada por Harry Benjamin continua, pois, a ser a leitura adotada pelo modelo médico que, em vez de reconhecer as pessoas trans como pessoas de direitos, as considera como patológicas.

Os procedimentos recomendados, reconhecidos e adotados no contexto ocidental são estabelecidos, atualmente, através dos já referidos SOC, da WPATH, e fornecem as linhas orientadoras para a decisão relativa ao (não) encaminhamento dos sujeitos para a cirurgia. Estes protocolos foram criados com o objetivo de garantir a saúde mental e física das pessoas com não conformidade entre o sexo e o gênero (Coleman et al., 2011; WPATH, 2012). Todavia, têm surgido inúmeros problemas associados aos SOC e deles decorrentes, mostrando que estes não têm correspondido a todas as realidades trans (FernándezFígares, 2010; Nieder; Richter-Appelt, 2011). Há percursos de vida trans que não estão incluídos

9 Precisamente pelas tentativas sucessivas de modificar a identidade com que a pessoa se identificava não serem bem-sucedidas, Benjamin entendeu que uma vez que a psicoterapia não conseguia que a pessoa se identificasse com uma identidade correspondente ao seu sexo, então a única possibilidade era "reparar" o corpo para que a conformidade entre sexo e gênero pretendida fosse dotada de legibilidade àquela época (Rodrigues, 2016). 
nos SOC ou são opostos a esses procedimentos, afinal, há pessoas que desejam o tratamento hormonal, mas não pretendem submeter-se à cirurgia. Se as situações descritas por pessoas trans que recorrem aos serviços de saúde não estão incluídas nos SOC ou são opostas a estes, os/as psicólogos/as e os/as médicos/as podem não autorizar o processo de mudança de sexo. Se essas pessoas desejarem mudar de sexo, a não autorização pode colocar em risco a sua saúde física e psicológica, contrariando os objetivos dos procedimentos dos SOC e pondo em risco a garantia da saúde mental e física das pessoas trans (Carvalho, 2010).

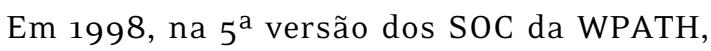
foram enumeradas cinco fases para a intervenção com transexuais, ${ }^{10}$ sendo uma delas o "teste de vida real". ${ }^{11} \mathrm{O}$ "teste de vida real" foi considerado como uma prova necessária, anterior aos tratamentos hormonais e cirúrgicos, sendo designada como uma fase não "medicamente comprometida", ${ }^{12}$ uma vez que não coloca em risco a vida da pessoa. Esta fase é socialmente a fase mais comprometida/prejudicial de todo o processo porque expõe a pessoa trans a uma possível perda da sua família e do seu trabalho, entre outras situações, que podem ser irreversíveis (Fernández-Fígares, 2010).

Em 2008, a WPATH publica um documento concordando com a definição de transexualidade, apresentada pela American Psychiatric Association, como perturbação mental. Esse documento refere que a mudança física de sexo é eficaz para o tratamento dos/as transexuais e incluiu a "experiência de vida real" ${ }^{13}$ como um dos procedimentos de mudança de sexo (Fernández-Fígares, 2010). Esta publicação mantém o caráter patológico das vivências transexuais, bem como a prescrição de critérios médicos para a "integração" das transexualidades.

A patologização das identidades trans tem se traduzido na contínua insistência de entender as pessoas transexuais como sujeitos que assumem a intervenção no corpo como a única solução para a sua construção identitária (Nieder; RichterAppelt, 2011). Para as pessoas trans que não desejam intervenções médicas, a possibilidade e a viabilidade oferecida pelo modelo médico de tratamento tornam o seu trajeto de vida mais complicado (Nieder; RichterAppelt, 2011), uma vez que os critérios de diagnóstico se baseiam numa trajetória transexual única, partindo da ideia de que todas as pessoas transexuais desejam mudar de sexo (Suess, 2010). Esta situação manifesta a falta de assistência a casos que não desejam progredir para a cirurgia ou para a terapia hormonal e a casos que não se encaixam na descrição do que é um/a "verdadeiro/a" transexual (Carvalho, 2010).

A $6^{\mathrm{a}}$ versão dos SOC faz referência à existência de uma variedade de caminhos terapêuticos. Os/as profissionais apercebem-se, cada vez mais, de que nem todas as pessoas transexuais necessitam e/ou desejam a totalidade dos elementos da terapia tripartida ${ }^{14}$ (Suess, 2010). Esta deixa de ser o único caminho, surgindo, paulatinamente, a necessidade de uma atenção individualizada com opções múltiplas (Lev, 2009).

As práticas médicas de atenção específica para as pessoas trans têm adotado os SOC, contudo, são interpretadas de forma muito distinta, não apenas por cada país, com seus contextos de aplicação específicos, mas também pelas diferentes equipes de profissionais da saúde. Além das diferenças nos modelos de aplicação, os SOC tendem a manter um caráter patologizador das experiências trans, apesar de, na sua $7^{\mathrm{a}}$ versão (WPATH, 2012) ${ }^{15}$, haver uma tentativa de salientar a variedade de experiências trans, ao distinguir a "disforia de gênero" da "variabilidade de gênero”, passando de um paradigma de avaliação da identidade para um paradigma de avaliação/medição de sofrimento (Platero, 2014; STP 2012, 2012).

\footnotetext{
10 O diagnóstico, a psicoterapia, o "teste de vida real”, a terapia hormonal e a cirurgia de redesignação sexual.

11 Nesta fase, segundo estes critérios, o indivíduo deve aprender, durante dois anos de acompanhamento, a viver segundo as normas culturalmente determinadas para o gênero ao qual sente pertencer. A experiência de vida real significa que os/as profissionais observam se as pessoas vivem de acordo com o gênero ao qual sentem pertencer na sua vida real (Missé, 2014). 12 Que não coloca em causa, que não acrescenta risco à pessoa. 13Anteriormente, este procedimento era designado por "teste de vida real".

14 A terapia tripartida ou tratamento triádico integra a avaliação psicológica, o tratamento endocrinológico e a intervenção cirúrgica (Fernández-Fígares, 2010).

15As revisões anteriores foram realizadas em 1980, 1981, 1990, 1998 e 2011.
} 
Segundo Miquel Missé (2014), no âmbito clínico, muitas pessoas trans, ao ouvirem os critérios a adotar para se ser um "verdadeiro transexual", incorporam estes discursos médicos para se definir e explicar a si. Mais do que um ato consciente, tratase frequentemente de um ato de sobrevivência. É ilustrativo o caso de uma criança de 7 anos que respondeu à seguinte pergunta: "Por que é que antes eras um rapaz e agora és uma rapariga?". A resposta foi a seguinte: "Porque tinha um cérebro de rapariga, num corpo de rapaz". Como refere Miquel Missé (2014), não se compreende o que surgiu primeiro: a experiência transexual ou os critérios de diagnóstico (discurso médico). Mesmo que não se saiba, o mais importante é que o discurso existe e tem impactos concretos na vida das pessoas. 0 modelo médico cria no imaginário coletivo a ideia de que todas as pessoas com inconformidade entre o sexo e o gênero desejam a cirurgia; patologiza a não conformidade de gênero e reforça que esta só poderá ser "curada" no bloco operatório; reitera que o único tratamento de "cura" é a mudança corporal, especialmente através da cirurgia de redesignação sexual (Missé, 2014).

Apesar de inúmeras pessoas relatarem "sentimentos" de rejeição pelo seu corpo em virtude da não conformidade entre o sexo e o gênero e desejarem modificações corporais, outras não relatam tais sentimentos, ainda que desejem modificar o seu corpo, não desejam realizar a cirurgia de redesignação sexual. A forma como as pessoas vivem e constroem os seus corpos é, assim, plural (Missé, 2014).

Segundo Carneiro (2006), importa reconhecer que a "feminilidade" e a "masculinidade" são categorias flexíveis, subjetivas e construídas socialmente. Nesta medida, a identidade de gênero refere-se à forma como as pessoas se identificam e constroem um sentido de si enquanto homens ou mulheres, assim como à forma como recusam essas identificações.
É difícil que um processo terapêutico tenha êxito se uma pessoa se vê obrigada a reproduzir uma narrativa específica, a do modelo médico, para poder ter um diagnóstico que lhe possibilita ter acesso aos tratamentos médicos e à mudança da identidade legal (exigência vigente em alguns países). Estes processos terapêuticos, que deveriam ser de acompanhamento, tornam-se em processos de avaliação e, por consequência, de julgamento das pessoas que solicitam apoio (Missé, 2014).

Além dos impactos decorrentes da tentativa de reproduzir o modelo médico com vista à legitimação da identidade, inúmeras pessoas trans não mantêm relação com outras pessoas trans após a realização da cirurgia de redesignação sexual ou, em geral, da mudança corporal. "Apagam” as suas experiências trans e passam a viver como homens ou mulheres, como se nunca tivesse existido uma não conformidade entre o sexo e gênero. Esse apagamento conduz, de resto, a uma inexistência de modelos trans e à desvinculação do próprio movimento trans. ${ }^{16}$

Com o reconhecimento que toda a identidade é subjetiva, plural e heterogênea, importa admitir que os seus limites não são claros. Embora exista hoje uma grande variedade de formas de experienciar as masculinidades e as feminilidades, as fronteiras sociais estão profundamente enraizadas (Viñuales; Guasch, 200o) e dificultam sobejamente a vida das pessoas que cruzam ou transcendem o binarismo de gênero (Bockting et al., 2005). As fronteiras sociais influenciam as práticas cirúrgicas e de modificações dos corpos de quem não reproduz a norma social. A adoção destas práticas cirúrgicas nos corpos não conformes emerge como a única possibilidade de estas pessoas serem desejáveis, aceites e legítimas. Secundando Miquel

Importa referir que em momento algum se pretende responsabilizar as pessoas trans da vinculação de relações a outras pessoas trans e com o movimento trans, nem defender compulsoriamente a necessidade de pertencimento, vinculação ou construção dessas relações e dessas comunidades. Apenas se pretende mostrar que, quando a pessoa trans evita legitimamente narrativas e vivencias pelas quais passou, faz com que outras pessoas trans não tenham modelos conhecidos e de valorização das suas vivências. Tal como refere Nuno Santos Carneiro (2006), pessoas envolvidas, quando comparadas com não envolvidos em ONGs LGBTs apresentam níveis mais elevados de orgulho e de integração e avaliam a sua orientação sexual e/ou identidade de gênero como parte "fundamental e muito positiva" do que as define enquanto pessoas. No entanto, e de acordo com McCarn e Fassinger (1996), "forçar a participação" não é legítimo; além disso, a relevância da discriminação social é de tal forma vigente que "obrigar” à participação é esquecer que muitas vezes não se participa, porque não se pode e não porque não se queira; e finalmente, há pessoas que chegam à integração sem nunca terem tido qualquer forma de participação política/associativa. 
Missé (2014, p. 6o, tradução nossa), “o corpo que um deseja não será nunca gordo, feio, deformado ou transexual”.

\section{(Des)patologização das}

\section{transexualidades e a premissa da autodeterminação: considerações finais}

Acredito que aceitar ser patologizado é rasgar seus direitos civis, é infantilizar-se em troca de uma aceitação social (que nunca acontece), é descrever-se como ser sem escolha, é resignar-se com um destino infalível, é deixar em outras mãos o seu futuro e o seu presente,é negar que só temos presente e pretendemos um futuro ao sermos obra de um passado que também construímos, [...] é autorizar outrem a tutelar suas vidas e corpos, é doar aos inquisidores e carrascos o chicote que violenta com suas definições, laudos, testes, comprovações e todas as artimanhas que esses donos de mentes e almas utilizam para domar o instinto de toda a vida que existe: o instinto de existir como quiser. (Oliveira, 2014, p. 102)

Este excerto, da autoria de André Lucas Oliveira (2014), cientista social e homem trans, traz à discussão as implicações do processo de patologização das vivências trans e do direito à autodeterminação dos seus corpos e identidades. O significado que cada pessoa trans atribui à sua experiência/vivência é aquele que deve prevalecer, em detrimento de um modelo médico que, como vimos anteriormente, patologiza e que as considera homogêneas e sem autonomia para decidir sobre as suas vidas (Freire, 2020; Sennott, 2010).

Em 2009, partindo do reconhecimento das consequências negativas que a patologização provoca nas vivências das pessoas trans (Missé, 2014), foi lançada a campanha internacional Stop Trans Pathologization 2012 ${ }^{17}$ (STP 2012, 2012). Organizada pela Rede Internacional pela Despatologização Trans, a iniciativa visa retirar a perturbação de identidade de gênero do $\mathrm{DSM}^{18}$ e da CID, abolir o caráter obrigatório do diagnóstico psiquiátrico para os tratamentos hormonais e cirúrgicos e para alterar o nome e o sexo no registo civil. Esta campanha tornou-se numa das maiores mobilizações internacionais do movimento trans ${ }^{19}$ (Missé, 2014; Platero, 2014; Suess, 2010).

Desde 2009, a campanha STP 2012 convoca, sempre no mês de outubro, um Dia Internacional de Ação pela Despatologização Trans, com manifestações simultâneas e outras ações em diversas cidades do mundo (STP 2012, 2015). Em outubro de 2015, em razão da data estipulada, já tinham decorrido mais de 100 ações em 45 cidades de vários. Atualmente, o apoio à campanha conta com 397 grupos e redes de ativistas, instituições públicas e organizações políticas da África, América Latina, América do Norte, Ásia, Europa e Oceânia. Para além das mobilizações anuais em outubro, esta rede internacional realiza atividades de informação e divulgação da campanha (STP 2012, 2015).

A perspetiva da despatologização centra-se no questionamento dos processos de patologização trans, referindo que não é a pessoa trans que está doente, mas uma sociedade incapaz de conceber realidades fora do modelo social hegemônico (Missé, 2014; STP 2012, 2011). Raquel (Lucas) Platero (Nabal, 2015) refere numa entrevista que as pessoas trans não têm uma patologia, mas que apenas necessitam de apoio para poder viver conforme o que sentem.

Em resposta à preocupação de algumas pessoas trans de uma potencial perda dos direitos médicos, como consequência da despatologização das transexualidades, alguns textos da campanha STP

17200 grupos provenientes de quatro continentes apoiaram a campanha internacional STP 2012 (STP 2012, 2012). A versão revista do DSM foi anunciada para 2012, mas surgiu apenas em 2013.

18 Após a publicação da $5^{\mathrm{a}}$ versão do DSM, substituindo a perturbação de identidade de gênero por disforia de gênero, a campanha STP 2012 propõe a remoção da disforia de gênero do DSM-5. Esta nova edição do manual (DSM-5) continua a considerar, assim, a transexualidade como uma perturbação mental (Platero, 2014; STP 2012, 2013).

19Foram pessoas trans as impulsionadoras da campanha STP 2012, no entanto, rapidamente se criou vozes e lugares plurais de apoio a esta campanha, nomeadamente, profissionais da área da saúde e investigadores/as sociais (Garaizabal, 2010; Missé, 2014; Platero, 2014). 
2012 incluem, a par da principal necessidade de retirar a perturbação de identidade de gênero do DSM e do CID, a proposta de uma menção não patologizante do processo de mudança física de sexo no CID, ${ }^{20}$ com o objetivo de garantir a cobertura pública dos tratamentos hormonais e cirúrgicos para aquelas pessoas que o desejam (STP 2012, 2011; Suess, 2010).

Apesar do diagnóstico "possibilitar" um tratamento público através do apoio financeiro para as cirurgias de redesignação sexual, questionase os efeitos desse diagnóstico (Arán; Zaidhaft; Murta, 2008; Missé, 2014).

Face ao posicionamento da não aceitabilidade do diagnóstico (bio)psicomédico, como forma oficial de legitimar uma identidade, que por ser determinista tutela a vida das pessoas (Almeida, 2010; Oliveira, 2014; Rodrigues, 2016), Susan Stryker (2008) defende a despatologização propondo uma ação libertadora e plural de conceber as (des)construções trans em oposição aos modelos médicos de homogeneização dos corpos, dos significados de si, dos desejos e dos comportamentos das pessoas trans. Estas pessoas, segundo o modelo médico, têm sido consideradas como sujeitos "apropriados" de direitos, apenas quando passam por "dispositivos de normalização".

Belissa Andía (2009), uma das representantes da campanha STP 2012, refere que é fundamental evitar um falso dilema entre a despatologização e os direitos à saúde. Para a autora, a despatologização não é oposta ao reconhecimento do direito à saúde, nem significa uma desmedicalização universal e/ou indesejada por sujeitos que nela encontrem significações e que dela necessitem enquanto veículo de determinação dos seus corpos e das suas identidades. As posições de despatologização não defendem o acompanhamento médico e psicológico apenas em situações de mal-estar clínico - mesmo para quem está integrado/a do ponto de vista orgânico e psicossocial é defendido o direito aos serviços de saúde, que podem continuar a ser necessários (e tendem a continuar a ser), tal como continuam a ser para todas as pessoas ao longo das suas vidas. O serviço psicológico/ médico necessita, unicamente, de saber que estas circunstâncias são possíveis, confiar na pessoa que pede ajuda, porque não há meios de objetivar essa necessidade e acompanhar e informar os/as trans sobre as implicações das suas decisões (FernándezFígares, 2010; Hammarberg, 2010).

Apesar das identidades trans não serem, como temos advogado, uma patologia, algumas pessoas trans necessitam de acompanhamento médico e reivindicam, compreensivelmente, um serviço público de qualidade para aceder aos tratamentos hormonais e/ou às cirurgias. 0 desejo de modificação corporal das pessoas trans é legítimo e, por isso, a sua modificação deve ser autodeterminada.

Segundo André Lucas Oliveira (2014), não é fácil viver em esferas que socialmente são apontadas como estando fora da "norma" e viver num corpo que, em algumas situações, é considerado um corpo abjeto. Neste sentido, deve-se assegurar o acesso à saúde com qualidade, problematizando, no entanto, os contextos que levam as pessoas trans à necessidade de alterar os seus corpos (Missé, 2014). ${ }^{21}$

Nem todos os países (e.g., Portugal, França, Suécia e Espanha) se posicionam a favor da patologização, mesmo que no DSM-5 essa situação esteja descrita como patológica (Oliveira, 2014; Platero, 2014; Sanmartín, 2010), uma vez que reconhecem as pessoas trans com direito de autonomia e de gestão sobre os seus corpos e identidades, fundados no reconhecimento dos direitos humanos destas pessoas.

De fato, algumas sociedades estão organizadas de tal forma, que conceber esta ideia de corpo desconforme não é aceitável, delegando ao poder médio a ação de patologizar e "disciplinar" as experiências humanas, neste caso dos corpos e gêneros não conformes. Os médicos/as tornam-se assim "guardiões/ãs do sistema binário de sexo/gênero (Missé, 2014). Este poder está ancorado também à ideia de que a regulação

20 A diferença do DSM do CID é que o DSM se refere, exclusivamente, a doenças mentais, enquanto o CID, inclui, para além dos critérios de diagnóstico das doenças, processos de atenção médica não baseados em doenças.

21Amets Suess, sociólogo, ativista trans e um dos coordenadores da campanha STP 2012 alega que as propostas de despatologização não pressupõem desmedicalização, ou seja, o direito do acesso à saúde para intervenções corporais se as pessoas trans o desejarem. Reforça, ainda, que a comparticipação pelo sistema público de saúde deve ser garantida, uma vez que a despatologização e a medicalização não são dois objetivos opostos, mas que permitem, efetivamente, o cumprir de Direitos Humanos fundamentais (STP 2012, 2011). 
dos corpos tem que acompanhar a regulação das identidades (sociais) e, assim sendo, os processos de modificação corporal tornam-se numa única forma de manter a conformidade de gênero (Oliveira, 2014). Em outras palavras, os processos devem seguir as normas de gênero (sexo masculino - gênero masculino e sexo feminino - gênero feminino) e de orientação sexual heterossexual como as únicas possíveis e aceitáveis (Butler, 2009; Oliveira, 2014).

Também segundo o sociólogo e ativista trans Miquel Missé (2014), o corpo trans tem sido exposto num paradigma do "erro" como se tivesse acontecido um problema em algum momento da vida de uma pessoa. Este paradigma enfatiza que as pessoas trans nasceram num corpo errado, mas que, afortunadamente poderão corrigi-lo e recuperá-lo. O paradigma do "erro" tem prejudicado muito mais as pessoas trans do que lhes tem trazido benefícios porque incorpora a ideia de que como as pessoas "sentem" que aquele corpo não é seu, tendem a maltratá-lo, mutilá-lo e destruí-lo. Posto isto, manter o paradigma do erro e a necessidade de corrigi-lo e recuperá-lo comporta os seus riscos (Garaizabal, 2010; Missé, 2014; Platero, 2014).

Para além de todas as questões implicadas no processo de patologização das identidades trans, simbolicamente estes corpos têm vindo a ser também designados como corpos abjetos e "monstruosos" (Oliveira, 2014; Platero; Rosón, 2012; Stryker, 2013). Estes corpos, para serem aceitos, têm vindo a passar por "dispositivos de normalização" heteronormativos (e, por decorrência, resultando possivelmente em vivências transnormativas). Manter a patologia nestes corpos é manter a ideia de que estes corpos apenas serão desejáveis e poderão desejar passando por um processo de "disciplinarização" heteronormativa ${ }^{22}$ e cisnormativa, ${ }^{23}$ fazendo com que haja um processo de hierarquização e de legitimação dos corpos e das vidas das pessoas de acordo com estes sistemas determinados (Butler, 2009; Louro, 2009; Oliveira, 2014, Teixeira, 2013).
Uma pessoa trans tem acedido à saúde com o rótulo "trans", mas esse rótulo/diagnóstico só ocorre quando as pessoas se tornam absolutamente "obedientes" a um sistema que tem o poder de tentar normalizar os seus corpos e as suas identidades. Quando as pessoas se tornam desobedientes, esse acesso à saúde é bloqueado, originando trajetos de opressão acrescida para a estas pessoas.

Segundo alguns/as autores/as, quando se fala de pessoas desobedientes, fala-se de pessoas que estão perante uma situação de não seguir o modelo médico que diz como os homens e as mulheres devem ser e se comportar. Ao não reproduzir o modelo médico, poderá condicionar a legitimação da sua identidade (Braz, 2018; Missé, 2014; Oliveira, 2014). Por exemplo, se uma pessoa adota um comportamento que desconstrua alguns estereótipos de gênero, poderá ser deslegitimada pelo/a profissional de saúde (Oliveira, 2014).

Posto isto, o modelo médico (patologizador) tem impacto na própria construção identitária dos sujeitos. As pessoas que passam por processos médicos, frequentemente, imprimem/reproduzem construções de masculinidades e feminilidades estereotipadas. Estas reproduções estereotipadas de algumas pessoas trans pode se explicar, também, pelo fato de que socialmente se reforça a ideia de que as pessoas trans são "uma má cópia do gênero em que vivem”, desvalorizando as suas construções e desconstruções identitárias. ${ }^{24}$ Algumas pessoas trans reproduzem estereótipos de gênero, precisamente, como forma de se reafirmar e, por consequência, se legitimar. Também, algumas pessoas trans para poder aceder à saúde criam as narrativas legítimas do modelo médico, expressando o desejo de viver no outro gênero desde a infância, sentimento de rejeição da genitália e ser heterossexual (Missé, 2014).

A perspetiva da despatologização se centra na premissa do direito das pessoas trans à sua autodeterminação. Assumir essa premissa acarreta, assim, em problematizar os modelos, mas também as próprias vidas (Missé, 2014). A título de exemplo,

\footnotetext{
22 Este processo de “disciplinarização” heteronormativa é baseado nas leituras de Judith Butler (20og), mas também é colocada a tónica na cisnormatividade. Isto é, os corpos cis (não trans) são mais valorizados, legítimos, aceites, reconhecíveis e reconhecidos como humanos do que os corpos trans.

23 Considerando que apenas homens com pénis e mulheres com vaginas são aceites e desejáveis.

24A questão de uma boa ou má “cópia” não se coloca neste trabalho, já que, como expõe Judith Butler (2004) numa ideia sua bem conhecida, o gênero é, afinal e sempre, essa cópia sem original.
} 
Miquel Missé (2014, p. 71, tradução nossa) refere: "nosso corpo não tem nenhum problema. O problema é do sistema que não sabe em que gaveta ordená-lo, classificá-lo, lê-lo. Mas claro, o bloco operatório é muito mais económico e menos questionador que a mudança social”.

Nem todas as pessoas se reveem no paradigma da patologização das transexualidades e, por isso, quem não se identifica com este modelo tem o direito de construir o seu próprio modelo explicativo (Missé, 2014). Para o movimento da despatologização, deve-se construir como imaginário coletivo a pluralidade de trajetos e legitimidade das identidades trans. Imaginário oposto ao construído pelo modelo biomédico de que a tutela médica é a única que confere legitimidade às identidades trans (Platero, 2014). Neste sentido, os Estados devem implementar políticas que ratifiquem as declarações internacionais de direitos humanos, reconhecendo e promovendo o acesso à saúde sem que, para isso, a pessoa tenha que ser patologizada, assumindo esse compromisso com os princípios feministas e de justiça social (Carvalho, 2014).

Segundo Shannon Sennott (2010), os/as profissionais que têm poder sobre as designações em torno da temática trans devem imergir na população trans para tomar decisões informadas sobre o futuro da "disforia de gênero", reconhecendo que os argumentos apresentados pelos/as defensores/ as da remoção desta perturbação são baseados na não estigmatização das pessoas trans. Tais profissionais devem se fundar nos princípios feministas que têm como preceito e ideia de que, em um mundo socialmente justo, qualquer tipo de sexo/gênerogênero não deveria ser patologizado.

Efetivamente, os/as profissionais devem ter a função de acompanhar as pessoas trans na sua autodeterminação, reconhecendo a sua experiência como seres humanos plurais e não como patológicos (Jesus, 2012), assumindo a despatologização do gênero como o percurso mais libertador e emancipatório (Butler, 2009; Carvalho, 2014).

A crítica ao modelo que patologiza as experiências e os trajetos de vida trans é assim assumida, no presente trabalho, através do (re)conhecimento dos impactos negativos que a adoção deste modelo tem na vida concreta das pessoas trans (e.g., estigma, violência e inexistência de autonomia) (Platero, 2014). Preconiza-se aqui a importância de considerar o trabalho dos/as profissionais de saúde no acompanhamento dos trajetos de vida trans, se assim as pessoas o desejarem, em oposição ao modelo biomédico que mantém a patologia dos trajetos de vida trans e, ao valorizar a "institucionalização da normalização" dos corpos e identidades trans, temse tornado o "guardião" das modificações destes corpos e identidades (Coimbra, 1995; Platero, 2014).

\section{Referências}

ALMEIDA, G. Reflexões iniciais sobre o processo transexualizador no SUS a partir de uma experiência de atendimento. In: ARILHA, M.; PISANESCHI, T.; CRENN, T. Transexualidade, travestilidade e direito à saúde. São Paulo: Oficina Editorial, 2010. p. 117-147.

ANDÍA, B. Fundamentación de la campaña contra la patologización de la identidad de género: alto a la patologización trans, 2012. Bruselas: Secretaría Trans de ILGA, 2009.

APA - AMERICAN PSYCHIATRIC ASSOCIATION. Manual de diagnóstico e estatística dos distúrbios mentais. 3. ed. Lisboa: Livros Técnicos e Científicos, 1986.

APA - AMERICAN PSYCHIATRIC ASSOCIATION. Manual of mental disorders. 4. ed. Washington, DC, 1994.

APA - AMERICAN PSYCHIATRIC ASSOCIATION. Manual de diagnóstico e estatística das perturbações mentais. 4. ed. Lisboa: Climepsi, 2002.

APA - AMERICAN PSYCHIATRIC ASSOCIATION. Diagnostic and statistical manual of mental disorders. 5. ed. Washington, DC, 2013.

ARÁN, M.; ZAIDHAFT, S.; MURTA, D. Transexualidade: corpo, subjetividade e saúde coletiva. Psicologia e Sociedade, Recife, v. 20, n. 1, p. 70-79, 2008. DOI: 10.1590/So10271822008000100008

BENJAMIN, H. Transsexualism and transvestism as psycho-somatic and somato-psychic syndromes. In: STRYKER, S.; WHITTLE, S. 
The transgender studies reader. New York:

Routledge, 1954/2006. p. 45-52.

BENJAMIN, H. The transsexual phenomenon. New York: The Julian Press, 1966.

BOCKTING, W. et al. Evaluation of a sexual health approach to reducing HIV/STD risk in the transgender community. Aids Care: Psychological and Socio-Medical Aspects of AIDS/HIV, Abingdon-on-Thames, v. 17, n. 3, p. 289-303, 2005. DOI: $10.1080 / 09540120412331299825$

BRAZ, C. Eu já tenho nome: itinerários de homens trans em busca de respeito. Habitus, Goiânia, v. 16, n. 1, p. 162-176, 2018. DOI: 10.18224/hab.v16i1.6367

BUTLER, J. Undoing gender. New York: Routledge, 2004.

BUTLER, J. Desdiagnosticando o gênero. Physis, Rio de Janeiro, v. 19, n. 1, p. 95-126, 2009. DOI: 10.1590/So103-73312009000100006

CARNEIRO, N. S. Ser, pertencer e participar: construção da identidade homossexual, redes de apoio e participação comunitária. 20o6. Tese (Doutorado em Psicologia) - Universidade do Porto, Porto, 2006.

CARVALHO, I. Transexualidade: vivência do processo de transição no contexto dos serviços de saúde. Acta Médica Portuguesa, Lisboa, v. 23, n. 6, p. 1001-1010, 2010.

CARVALHO, N. S. Gênero e sexualidade: intersecções em disputa. In: JESUS, J. G. Transfeminismo: teorias e práticas. Rio de Janeiro: Metanoia, 2014. p. 69-84.

CASTEL, P.-H. Algumas reflexões para estabelecer a cronologia do "fenômeno transexual" (1910-1995). Revista Brasileira de História, São Paulo, v. 21, n. 41, p. 77-111, 2001. DOI: 10.1590/So102-01882001000200005

CAULDWELL, D. O. Psychopathia transexualis. In: STRYKER, S.; WHITTLE, S. The transgender studies reader. New York: Routledge, 2006. p. 40-44.

COIMBRA, C. (Org.). Guardiães da ordem: uma viagem pelas práticas psi do Brasil do milagre. Rio de Janeiro: Oficina do Autor, 1995.
COLEMAN, E. et al. Standards of care for the health of transsexual, transgender, and gender-nonconforming people, version 7 . International Journal of Transgenderism, Abingdon-on-Thames, v. 13, n. 4, p. 165-232, 2011. DOI: $10.1080 / 15532739.2011 .700873$

COLL-PLANAS, G. Indroducción. In: MISSÉ, M.; COLL-PLANAS, G. El género desordenado: críticas en torno a la patologización de la transexualidad. Barcelona: Egales, 2010. p. 15-25.

DEVOR, A. H. Reed Erickson and The Erickson Educational Foundation. The Erickson Educational Foundation, [s.l.], 2013. Disponível em: <https://bit.ly/3uQXi2M>. Acesso em: 20 ago. 2020. DOCTER, R. F. Becoming a woman: a biography of Christine Jorgensen. Philadelphia: The Haworth Press, 2008.

FERNÁNDEZ-FÍGARES, K. Historia de la patologización y despatologización de las variantes de género. In: MISSÉ, M.; COLLPLANAS, G. El género desordenado: críticas en torno a la patologización de la transexualidad. Barcelona: Egales, 2010. p. 97-111.

FISK, N. Gender dysphoria syndrome: the how, the what, the why of a disease. In: LAUB, D. R.; GANDY, P. Proceedings of the second interdisciplinary symposium on gender dysphoria syndrome. Palo Alto: Stanford University Medical Center, 1973. p. 7-14.

FREIRE, L. Em defesa da dignidade: moralidades e emoções nas demandas por direitos de pessoas transexuais. Mana, Rio de Janeiro, v. 26, n. 2, e262205, 2020. DOI: 10.1590/1678-49442020V26n2a205

GARAIZABAL, C. Transexualidades, identidades e feminismos. In: MISSÉ, M.; COLL-PLANAS, G. El género desordenado: críticas en torno a la patologización de la transexualidad. Barcelona: Egales, 2010. p. 125-140.

HAMMARBERG, T. Derechos humanos e identidad de género. Estrasburgo: Council of Europe, 2010.

HOYER, N. (Ed.). Man into woman: the first sex change: a portrait of Lili Elbe. London: BlueBoatBooks, 1933/2004. 
JESUS, J. G. Orientações sobre identidade de gênero: conceitos e termos. Brasília, DF: Jaqueline Gomes de Jesus, 2012.

KING, D. Confusiones de género: concepciones psicológicas y psiquiátricas sobre el travestismo y la transexualidad. In: NIETO, J. A. Transexualidad, transgenerismo y cultura. Madrid: Talasa, 1998. p. 126-156.

LEV, A. The ten tasks of the mental health provider: recommendations for revision of the World Professional Association for transgender health's standards of care. International Journal of Transgenderism, Abingdon-on-Thames, v. 11, n. 2, p. 74-99, 2009. DOI: $10.1080 / 15532730903008032$

LOURO, G. L. Heteronormatividade e homofobia. In: JUNQUEIRA, R. D. Diversidade sexual na educação: problematizações sobre a homofobia nas escolas. Brasília, DF: Ministério da Educação: Unesco, 2009. p. 85-93.

MANCINI, E. Magnus Hirschfeld and the quest for sexual freedom: a history of the first international sexual freedom movement. London: Palgrave Macmillan, 2010.

MCCARN, S. R; FASSINGER, R. E. Revisioning sexual minority identity formation: a new model of lesbian identity and its implications for counseling and research. The Counseling Psychologist, Thousand Oaks, v. 24, n. 3, p. 508534, 1996. DOI: 10.1177/oo110ooog6243011

MEYEROWITZ, J. How sex changed: a history of transsexuality. Cambridge: Harvard University Press, 2002.

MISSÉ, M. Transexualidades: otras miradas posibles. 2. ed. Barcelona: Egales, 2014.

NABAL, E. Entrevista a Raquel (Lucas) Platero. BurgosDijital, Madrid, 25 maio 2015. Disponível em: <https://bit.ly/3wQde7j>. Acesso em: 24 out. 2020.

NIEDER, T.; RICHTER-APPELT, H. Tertium non datur: either/or reactions to transsexualism amongst health care professionals: the situation past and present, and its relevance to the future. Psychology \& Sexuality,
Abingdon-on-Thames, v. 2, n. 3, p. 224-243, 2011. DOI: $10.1080 / 19419899.2010 .545955$

OLIVEIRA, A. L. Os homens transexuais brasileiros e o discurso pela (des)patologização da transexualidade. In: JESUS, J. G. Transfeminismo: teorias e práticas. Rio de Janeiro: Metanoia, 2014. p. 87-105.

ORTEGA, E.; ROMERO-BACHILLER, C.; IBÁÑEZ, R. Discurso activista y estatus médico de lo trans: hacia una reconfiguración de cuidados y diagnósticos. In: PÉREZ SEDEÑO, E.; ORTEGA, E. Cartografías del cuerpo: biopolíticas de la ciencia y la tecnología. Madrid: Cátedra, 2014. p. 521-572.

PLATERO, R. L. (Org.). Trans*exualidades: acompañamiento, factores de salud y recursos educativos. Barcelona: Bellaterra, 2014.

PLATERO, R. L.; ROSÓN, M. De “la parada de los monstruos" a los monstruos de lo cotidiano: la diversidad funcional y sexualidad no normativa. Feminismo/s, Alicante, n. 19, p. 127-142, 2012. DOI: 10.14198/fem.2012.19.08

RODRIGUES, L. Viagens trans(género) em Portugal e no Brasil: uma aproximação psicológica feminista crítica. 2016. Tese (Doutorado em Psicologia) - Universidade do Porto, Porto, 2016.

SANMARTÍN, O. R. El gobierno pedirá a la OMS que no vea la transexualidad como una enfermedad. $E l$ Mundo, Madrid, 14 maio 2010. Disponível em: <https://bit.ly/3djFLdH〉. Acesso em: 24 out. 2020.

SENNOTT, S. Gender disorder as gender oppression: a transfeminist approach to rethinking the pathologization of gender non-conformity. Women \& Therapy, Abingdonon-Thames, v. 34, n. 1-2, p. 93-113, 2010. DOI: $10.1080 / 02703149.2010 .532683$ SOLEY-BELTRAN, P. (Org.). Transexualidad y la matriz heterosexual. Barcelona: Bellaterra, 2009. STOLLER, R. Biological substrates of sexual behavior. In: STRYKER, S.; WHITTLE, S. 
The transgender studies reader. New York:

Routledge, 1960/2006. p. 53-57.

STP 2012 - STOP TRANS PATHOLOGIZATION 2012. Comunicado da campanha STP 2012: reflexões sobre despatologização trans e direitos de saúde.

[S.l.], 2011.

STP 2012 - STOP TRANS PATHOLOGIZATION 2012. Reflexiones sobre los SOC-7. [S.1.], 2012.

STP 2012 - STOP TRANS PATHOLOGIZATION 2012. Desarrollos recientes relacionados con el proceso de revisión del DSM y de la CIE. [S.I.], 2013.

STP 2012 - STOP TRANS PATHOLOGIZATION

2012. Día Internacional de Acción por la Despatologización Trans. [S.l.], 2015.

STRYKER, S. Transgender history. Berkeley: Seal Press, 2008.

STRYKER, S. Prefacio. In: BALZER, C.; HUTTA, J. S. (Ed.). Transrespeto versus transfobia en el mundo: un estudio comparativo de la situación de los derechos humanos de las personas trans. Berlín: Transgender Europe, 2013. p. 12-17.

SUESS, A. Análisis del panorama discursivo alrededor de la despatologización trans: procesos de transformación de los marcos interpretativos en diferentes campos sociales. In: MISSÉ, M.; COLL-PLANAS, G. El género desordenado: críticas en torno a la patologización de la transexualidad. Barcelona: Egales, 2010. p. 29-54.

TEIXEIRA, F. Dispositivos de dor: saberes-poderes que (con)formam as transexualidades. São Paulo: Annablume, 2013.

VIÑUALES, O.; GUASCH, O. (Org.). Sobre el futuro de la identidad. Madrid: Reverso, 2000.

WHO - WORLD HEALTH ORGANIZATION. ICD-11 for mortality and morbidity statistics. Geneva, 2019.

WPATH - WORLD PROFESSIONAL ASSOCIATION FOR TRANSGENDER HEALTH. Normas de atenção à saúde das pessoas trans e com variabilidade de género. East Dundee, 2012.

\section{Contribuição dos autores}

Rodrigues, Santos Carneiro e Nogueira cooperaram para a escrita de todo o manuscrito com contribuições críticas e a revisão.

Recebido: 03/11/2020

Aprovado: 15/12/2020 


\section{Errata}

No artigo "História das abordagens científicas, médicas e psicológicas sobre as transexualidades e suas aproximações críticas", doi 10.1590/So104-12902021200768, publicado no volume 30, n⿳02 de 2021 da revista Saúde e Sociedade, primeira página, foi inserida nota de rodapé número 1:

\section{Leia-se:}

1 Este trabalho foi financiado pelo Centro de Psicologia da Universidade do Porto, Fundação para a Ciência e a Tecnologia (FCT UIDB/ooo50/2020). 